\title{
Effects of within-chain response delay upon post-delay operant performance ${ }^{\prime}$
}

\author{
JOHN G. CARLSON, UNIVERSITY OF MINNESOTA, \\ Minneapolis, Minnesota ${ }^{2}$
}

Operant responding of rats was delayed by withholding the response levers between the two components of a response chain. Latency and rate of responding in the second component were facilitated by a $10 \mathrm{sec}$ delay with respect to a $4 \mathrm{sec}$ delay. When the delay was increased to $50 \mathrm{sec}$, the facilitation of latency declined whereas the facilitation of response rate increased.

Several theorists (cf. Brown, 1961) have viewed delay or internuption of an ongoing response as a source of frustration analogous in its effects to nonreinforcement. However, it has not been established that the behavioral effects of response delay are, in fact, similar to those of nonreinforcement.

It has been consistently demonstrated with rats that frustrative nonreinforcement increases post-nonreinforcement response levels in both runway (cf. Amsel, 1958) and lever pressing contexts (e.g., Carlson, 1968). But several investigators have reported inconsistent effects of introducing an enforced delay into an instrumental response chain. For example, Holder, Marx, Holder, \& Collier (1957) have shown that delay of a running response produces an increase in speeds in the portion of a runway following the point of delay. In contrast, Wist (1961) and others have demonstrated that delay of responding produces a decrease in post-delay running speeds. The source of this disagreement is not clear since the procedures used in these studies differed in a number of ways. But it is possible that a lack of control inherent in the runway delay setting itself may have contributed to the differences.

For this reason, and in view of earlier success in adapting operant procedures to the study of nonreinforcement, the present experiment investigated delay of responding in an operant response setting. Delay was produced by withholding response levers for a period of time between the first and second components of a two-lever response chain.

Method. Eight 90-day-old male Long-Evans hooded rats served as Ss. Eighty-five per cent of ad lib body weights were maintained throughout the experiment.

Two operant conditioning chambers and programming equipment described previously (Carlson, 1968) were used. The distance from the response wall of the chamber to the opposite wall was reduced from 14 in. to 8 in.

The Ss were given two $30 \mathrm{~min}$ adaptation sessions, three days of magazine training ( 60 reinforcements per session), and ten days of lever-press training using the training procedures described in Carlson (1968). During the next 10 sessions, the following reinforcement schedule was in effect. A trial began with the onset of the house light and left jewel light and the insertion of the left (L) lever into the charaber. Fifteen responses on this lever (fixed ratio, $F_{L}$ 15) retracted the lever from the chamber and extinguished the jewel light. No reinforcement was detivered at this point. A mid-trial interval (MTI) of $2 \mathrm{sec}$ was then followed by the insertion of the right $(R)$ lever into the

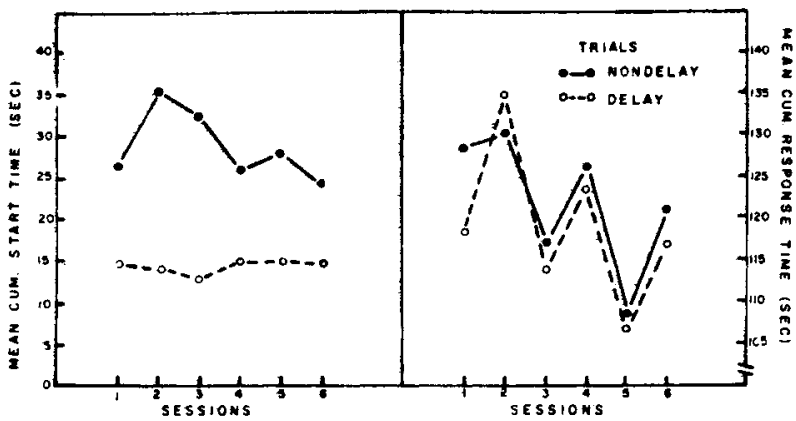

Fig. 1. Means of cumulative starting and response times on 10 delay and 10 nondelay trials. chamber and the onset of its corresponding jewel light. With the completion of $F R_{R} 15$, reinforcement was delivered (three $.045 \mathrm{~g}$ Noyes pellets), the lever was retracted, and the lights extinguished. An intertrial interval of variable length (mean $=30 \mathrm{sec}$ ) was then imposed. A daily session consisted of 20 such trials plus two initial warmup trials during which no data were collected.

There followed 20 sessions in which the duration of the MTI was varied to determine optimal testing and baseline conditions. ${ }^{3}$ In the last two sessions, the operating force requirement on the right lever was permanently increased to $45 \mathrm{~g}$ from its previous $15 \mathrm{~g}$. This was done in order to reduce the level of performance on $F R_{R} 15$ and avoid possible ceiling effects.

During the next six (test) sessions, on a random half of each day's trials (nondelay trials), the MTI was $4 \mathrm{sec}$ in duration. On the remaining trials (delay trials), the MTI was $10 \mathrm{sec}$.

Eight additional test sessions were then given on which for half the Ss the delay trial MTI was $30 \mathrm{sec}$ one day, $10 \mathrm{sec}$ the next, $30 \mathrm{sec}$ the next, etc. For the other four $\mathrm{Ss}$, these conditions were reversed, $10 \mathrm{sec}, 30 \mathrm{sec}, 10 \mathrm{sec}$, etc. For both groups, the nondelay trial MTI was 4 sec. These procedures were continued for another eight test days with the delay trial MTI either $10 \mathrm{sec}$ or $50 \mathrm{sec}$ on alternate days, again counterbalanced between the two groups. Since the results of the test with the $30 \mathrm{sec}$ maximum delay closely paralled those with the $50 \mathrm{sec}$ delay, only the data from the latter sessions will be reported.

Results. Starting and response times in each of the first six test sessions were cumulated separately for the $10 \mathrm{sec}$ delay and $4 \mathrm{sec}$ nondelay trials. Starting time was defined as the time to the first lever press following insertion of the right lever into the chamber. Response time was the time which elapsed from the first to the last lever press on $F_{R} 15$. These results are shown in Fig. 1 .

In the starting time measure (left half of Fig. 1), consistently shorter latencies on delay trials were apparent. An analysis of variance showed this effect to be significant $(F=10.65, \mathrm{df}=1 / 6$, $p<.025)$. A smaller and not as consistent trend in the same direction appeared in an analysis of response time. As shown in the right half of the figure, response time was facilitated on delay trials in all but Session $2(F=7.31, \mathrm{df}=1 / 6, \mathrm{p}<.05)$.

The results of the last eight test sessions, in which the MTI ranged from $4 \mathrm{sec}$ on nondelay trials to 10 and $50 \mathrm{sec}$ on delay trials, are shown in Fig. 2. The starting and response times on the right lever were averaged across all eight sessions.

Two different trends are evident. In the starting time measure, the effect of delay was to facilitate performance, but to a lesser extent when the delay was $50 \mathrm{sec}$ than when it was $10 \mathrm{sec}$ in duration. In individual contrasts, the following mean differences were statistically significant: $4 \sec -10 \sec (F=30.43, \mathrm{df}=1 / 9$, $\mathrm{p}<.0005) ; 4 \sec -50 \sec (\mathrm{F}=8.16, \mathrm{df}=1 / 9, \mathrm{p}<.025) ; 10 \sec -50$ $\sec (F=8.83, \mathrm{df}=1 / 8, \mathrm{p}<.025)$. On the other hand, the delay effect in the response time measure was directly' related to the duration of the delay interval, as the right half of the figure shows. Analyses on all of the contrasts in this measure showed only the 4 sec-50 sec mean difference to be significant $(F=5.87, \mathrm{df}=1 / 11$, $p<.05)$.

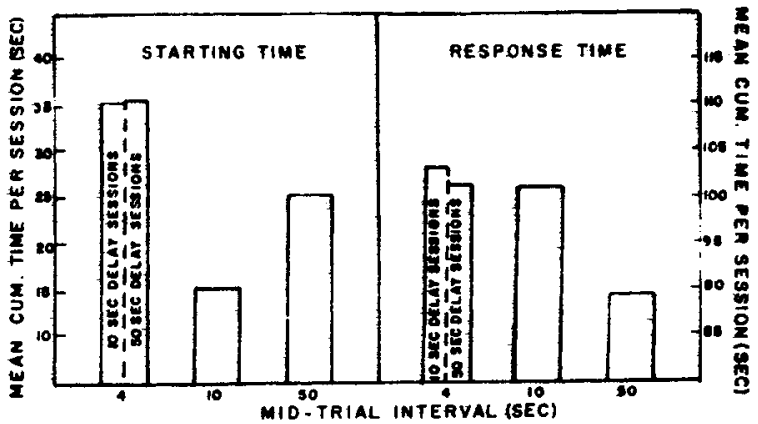

Fig. 2 Means of cumulative starting and response times per session following mid-trial intervals of 4,10 , and 50 sec. 
Discussion. From these results it may be concluded, first, that mid-chain response delay facilitated post-delay operant performance in terms of both latency and ongoing response rate. This effect is like that obtained in the runway by some investigators, and it supports a suggestion made by Davenport, Flaherty, \& Dyrud (1966) that delay of operant responding may have contributed to the effects of frustrative nonreinforcement in their study. Also, the similarity between the effects of response delay in the present experiment and the nonreinforcement effect obtained under comparable conditions (Carlson, 1968) lends some support to theories which treat both response delay and nonreinforcement as frustration variables.

Second, rate of responding was directly related to the duration of response delay using delays of 4,10 , and $50 \mathrm{sec}$. Holder et al (1957) obtained parallel results in a runway with delays of 1,15 , and $45 \mathrm{sec}$. These results point up the importance of this parameter and have relevance for Brown and Farber's hypothesis that the strength of frustration drive is a function of the degree of response interference (Brown, 1961, p. 204).

Third, in contrast to its effect on response rate, the duration of delay in the range sampled had a nonmonotonic effect on response latency. With increases in delay of responding beyond $10 \mathrm{sec}$, the facilitative effect of delay on response latency tended to diminish. This suggests that the starting time measure may have been more sensitive than ongoing response rate to the effects of competing responses possibly generated during the delay interval.

\section{REFERENCES}

AMSEL, A. The role of frustrative nonreward in noncontinuous reward situations. Psychol Bull, 1958, 55, 102-119.
BROWN, J. S. The motivation of behavior. New York: McGraw-Hill, 1961.

CARLSON, J. G. Effects of consummatory and instrumental response blocking. Unpublished doctoral dissertation, University of Minnesota, 1967.

CARLSON, J. G. Frustrative nonreinforcement of operant responding: Magnitude of reinforcement and response force effects. Psychon. Sci., 11, 9, 307-308.

DAVENPORT, J. W., FLAHERTY, C. F., \& DYRUD, J. R. Temporal persistence of frustration effects in monkeys and rats. Psychon. Sci., 1966, $6,411-412$,

HOLDER, W. B., MARX, M. H., HOLDER, E. E., \& COLLIER, G. Response strength as a function of delay of reward in a runway. J. exp. Psychol., $1957,53,316-323$.

WIST, E. R. Amount, delay, and position of delay of reinforcement as parameters of runway performance. J. exp. Psychol, 1962, 63, 160-166.

\section{NOTES}

1. This study is based on a dissertation (Carlson, 1967) and was supported in part by grants to the Center for Research in Human Learning, University of Minnesota, Grateful acknowledgement is due Dr. M. A. Trapold, who provided assistance with the research and this manuscript.

2. Now at the Department of Psychology, University of Hawaii, Honolulu, Hawaii 96822.

3. Details of these phases may be found in Carlson (1967). 